\begin{tabular}{|l|l|}
\hline & $\begin{array}{l}\text { HHS PUbic ACCOSS } \\
\text { Author manuscript } \\
\text { Prev Med. Author manuscript; available in PMC } 2017 \text { October } 11 .\end{array}$ \\
\hline
\end{tabular}

Published in final edited form as:

Prev Med. 2016 October ; 91 Suppl: S1. doi:10.1016/j.ypmed.2016.07.001.

\title{
Tobacco control in Africa
}

Indu B. Ahluwalia, MPH, PhD*, Office on Smoking and Health, National Center for Chronic Disease Prevention and Health Promotion, Centers for Disease Control and Prevention, Atlanta, GA, United States

René A. Arrazola, MPH, and

Office on Smoking and Health, National Center for Chronic Disease Prevention and Health Promotion, Centers for Disease Control and Prevention, Atlanta, GA, United States

\section{Ahmed E. Ogwell, OUMA MPH, MPhil \\ Regional Office for Africa, World Health Organization, Brazzaville, Congo}

Tobacco use is a leading cause of preventable morbidity and mortality worldwide, with nearly 6 million tobacco-attributable deaths every year (World Health Organization, 2012). If current trends continue, tobacco use is expected to result in an estimated 1 billion deaths by the end of the century, with most from low- and middle-income countries (Mathers and Loncar, 2006).

Cigarette smoking is the most common form of tobacco use in most countries, and the majority of adult smokers first try cigarettes before age 18 (CDC Foundation, 2015; Anon., 2012). Limiting access to cigarettes among youth is an effective strategy to curb the tobacco epidemic by preventing smoking initiation and reducing the number of new smokers (CDC Foundation, 2015; Anon., 2012; DiFranza, 2012). To reduce the threat posed by tobacco to public health, the World Health Organization (WHO) has promoted the ratification of the WHO Framework Convention for Tobacco Control (FCTC) and has developed demand reduction tools (http://www.who.int/fctc/reporting/en/). The "MPOWER" demand reduction package includes the following strategies to assist countries in addressing the tobacco epidemic: Monitor tobacco use; Protect people from second hand smoke; Offer help to quit tobacco use; Warn about the dangers of tobacco; Enforce bans on tobacco advertising and promotion; Raise taxes on tobacco products.

With the continuing decline in cigarette smoking in high-income countries, Africa has become a prime market for the tobacco industry because of its economic growth and demographic and legislative climate (World Health Organization, 2012; WHO, 2015; The World Bank, n.d.; Tumwine, 2011; Doku, 2010; Gilmore et al., 2015). Although most African countries have ratified the WHO FCTC, progress in the implementation of WHO FCTC articles has been weak to modest, and existing legislation often does not meet the standards set by WHO (Gilmore et al., 2015). It is thus important to measure progress in the comprehensive implementation of the demand reduction measures in the WHO FCTC to reduce tobacco use. This aim can be achieved with credible and timely data to measure the

*Corresponding author. iaa2@cdc.gov. 
impact of tobacco prevention and control efforts through surveillance systems, such as the Global Adult Tobacco Survey (GATS) and Global Youth Tobacco Surveillance (GYTS) (http://nccd.cdc.gov/gtssdata). The GYTS and GATS data can assist in defining the tobacco landscape, determining information needs, identifying opportunities for prevention and control, and developing population-based programs and policies. The potential for an increase in tobacco use in Africa is a major public health concern; using these surveillance resources, countries on the continent can continue to monitor, implement, and enforce measures to protect the public from the harmful effects of tobacco use and secondhand smoke exposure (Baleta, 2010).

The articles in this supplement focus on a number of important areas for tobacco prevention and control, using surveillance data collected by various countries in Africa. The papers provide an overall status of FCTC, including demand reduction strategies implemented, and identify opportunities for enhancing programs and policies that protect people from the harms of tobacco use and secondhand smoke exposure. GYTS data are presented on multiple topics throughout the supplement, including youth tobacco use and access to cigarettes, marketing of tobacco products to youths, and the relationship between secondhand smoke exposure and youth susceptibility to tobacco use. The studies in this supplement are poised to fill an important gap in the literature and point to the future work that can help combat tobacco use on a continent with a young, vibrant population and growing economies. Reducing tobacco use in Africa is an urgent public health priority, and tobacco use prevention and control strategies are a best buy in public health. The WHO FCTC and its guidelines, as well as the package of demand reduction measures developed by WHO, provide concrete steps to equip countries to address tobacco use and secondhand smoke exposure in Africa.

\section{References}

Anon. Preventing Tobacco Use among Youth and Young Adults: A Report of the Surgeon General. US Department of Health and Human Services, Centers for Disease Control and Prevention; Atlanta, GA: 2012. (http://www.surgeongeneral.gov/library/reports/preventing-youth-tobacco-use/fullreport.pdf)

Baleta A. Africa's struggle to be smoke free. Lancet. 2010; 375(9709):107-108. [PubMed: 20109875]

CDC Foundation. Global adult tobacco survey (GATS) atlas. 2015. http://www.cdc.gov/tobacco/ global/gtss/tobacco_atlas/

DiFranza JR. Which interventions against the sale of tobacco to minors can be expected to reduce smoking? Tob Control. 2012; 21:436-42. [PubMed: 21994275]

Doku D. The tobacco industry tactics-a challenge for tobacco control in low- and middle-income countries. Afr Health Serv. 2010; 10(2):201-203.

Gilmore AB, Fooks G, Drope J, et al. Exposing and addressing tobacco industry conduct in lowincome and middle-income countries. Lancet. 2015; 385(9972):1029-1043. [PubMed: 25784350]

Mathers CD, Loncar D. Projections of global mortality and burden of disease from 2002 to 2030. PLoS Med. 2006; 3(11):e442. http://dx.doi.org/10.1371/journal.pmed.0030442. [PubMed: 17132052]

The World Bank. Population estimates and projections. Secondary population estimates and projections; dhttp://data.worldbank.org/data-catalog/population-projection-tables

Tumwine J. Implementation of the framework convention on tobacco control in Africa: current status of legislation. Int J Environ Res Public Health. 2011; 8:4312-4331. [PubMed: 22163209] 
WHO. WHO Report about Global Tobacco Epidemic, 2015: Raising Taxes on Tobacco. WHO; Geneva, Switzerland: 2015. (http://apps.who.int/iris/bitstream/ 10665/178574/1/9789240694606_eng.pdf?ua=1)

World Health Organization. WHO global report: mortality attributable to tobacco. 2012. http:// apps.who.int/iris/bitstream/10665/44815/1/9789241564434_eng.pdf 